\title{
When Good Goes Bad: The Effects of High Negative Affectivity on Pressure to Produce
}

\author{
Kenneth Harris ${ }^{1}$, Lisa Russell ${ }^{2}$ \& Ranida Harris ${ }^{3}$ \\ ${ }^{1}$ Associate Professor of of Management, School of Business, Indiana University Southeast, United States \\ 2 Assistant Professor of Strategic Management and Entrepreneurship, School of Business, Indiana University \\ Southeast, United States \\ 3 Associate Professor of Management Information Systems, School of Business, Indiana University Southeast, \\ United States
}

Correspondence: Lisa Russell, Assistant Professor of Strategic Management and Entrepreneurship, School of Business, Indiana University Southeast, United States. E-mail: lismruss@ius.edu

Received: May 11, 2015

Accepted: June 12, 2015

Online Published: August 5, 2015

doi:10.5430/jms.v6n3p1

URL: http://dx.doi.org/10.5430/jms.v6n3p1

\begin{abstract}
Pressure to produce at the workplace is omnipresent, and in many ways a necessary situation. Although pressure to produce helps to motivate or drive employee performance, it is likely to be associated with negative outcomes. In this study, we examine three outcomes (job satisfaction, role overload, and perceived organizational support) to assess their linkages with pressure to produce. Based on person-situation theory, we also investigate negative affectivity (NA) as a moderator of pressure to produce-outcome relationships. We examine these hypotheses in a sample of 220 technology end-users from a wide range of jobs. Our results support our hypotheses that pressure to produce is negatively related to desired work outcomes, and that NA intensifies the associations between pressure to produce and negative consequences.
\end{abstract}

Keywords: negative affectivity, pressure to produce, perceived organizational support, role overload, job satisfaction

\section{Introduction}

All employees are expected to be productive at some level. For technology end-users, those employees who complete the majority of their work on computers, this pressure to produce is likely to be present in multiple ways. Technology end-users know that their work can be tracked, they are often times constantly connected, and there's even the potential that work can be completed after "normal" work hours (Ayyagari, Grover, \& Purvis, 2011). As employers 'Millennialize' the workplace (Ferri-Reed, 2014) by embracing social networking services (SNS) and other job-related technology, employees face additional technostressors (Majer, Laumer, Weinert, \& Weitzel, 2015). However, different workplaces are likely to have different pressures to produce. On a continuum, organizations range from less demanding companies to more intense, highly competitive organizational environments.

For these reasons, pressure to produce is an important variable to examine for this sample of workers. Although managers realize pressure to produce can likely have both positive and negative effects, less is known about the specific associations between this pressure and workplace outcomes. In this study, we examine two employee attitudes, job satisfaction and perceived organizational support (POS), and a stress-related variable, role overload. Job satisfaction is defined as the overall feeling individuals have about their jobs (Spector, 1997), POS is defined as "global beliefs concerning the extent to which the organization values their contributions and cares about their well-being" (Rhoades \& Eisenberger, 2002, p. 698), and role overload is defined as situations where employees perceive too many expected demands (i.e., responsibilities or activities) in light of their available resources such as time, ability, and aptitude (Peterson, Smith \& Akande et al., 1995; Rizzo, House, Lirtzman, 1970). By examining both positive and negative variables, we are able to better determine the ultimate impacts of pressure to produce.

Realizing that pressure to produce, which is necessary at some level in organizations for job performance, is likely to be associated with undesirable attitudinal and stress-related variables, we don't think it will influence all employees equally. Based on person-situation theory (Mischel \& Shoda, 1995), we suggest that negative affectivity (NA) that will play a role in how employees respond to situational levels of pressure to produce. Negative affectivity is a stable 
personality trait associated with experiencing higher levels and more frequent negative emotions, moods, and an overall more negative self-view (Watson, 2000). Based on person-situation theory, we posit that higher levels of NA will intensify the undesirable impact of pressure to produce on desired outcomes.

The goals of this study are twofold. First, we want to investigate less studied outcomes of pressure to produce to determine its impact on technology end-users. Second, we want to examine how NA influences the pressure to produce - consequence associations. In so doing, we will shed light on the importance of examining a negative personality trait and its impact on those individuals who complete the majority of their work using technology.

\subsection{Pressure to Produce}

Pressure to produce is defined as "the extent to which management exerts pressure on employees to produce" (Slocum, Cron, Hansen, \& Rawlings, 1985, p.140). Pressure to produce may vary by both the firm type, national orientation toward technology, dissemination of 'discretionary learning' forms of work organization, organizational approach to modernization of production techniques, government regulation, and global pressures (Alasoini, Ramstad, Heikkiiä, Ylöstalo, 2010). At the workplace, all employees, including technology end-users, experience a certain pressure to produce. This pressure is an essential aspect of the job, as employees are not likely to work as hard and produce at their highest levels without some aspects of pressure (LePine, Podsakoff, \& LePine, 2005).

However, along with the positive performance-related outcomes associated with pressure to produce, this situational variable is also linked to some negative consequences. In particular, pressure to produce is likely to be associated with lower levels of employee attitudes and higher levels of role overload. Research investigating variables that create incentives and pressures for worker outcomes support these relationships. Researchers (Harris, Lambert, \& Harris, 2013) found that abusive supervision, a particularly negative stressor influencing performance and productivity, is negatively related to perceived organizational support among technology workers. Among Turkish banking and insurance employees, perceived organizational support mediated the relationship between perceptions of organizational justice and job satisfaction (Demircan Çakar and Yildiz, 2009).

Specifically focusing on technology end-users, these employees can have pressure exerted on them through constant interconnectivity, the ability to have their work tracked, and the ability to work continuously to complete their jobs (on computers). As managers exert higher levels of pressure to produce on their employees, employees are likely to respond in certain ways including working harder and harder, feeling the pressure of more work to be performed, and perceptions that the organization's primary concern is for productivity. Based on these arguments, we anticipate pressure to produce is negatively linked to the individual level consequences of job satisfaction and POS, and positively linked with role overload. Thus, we predict that:

Hypothesis 1a: Pressure to produce is negatively associated with job satisfaction.

Hypothesis 1b: Pressure to produce is negatively associated with POS.

Hypothesis 1c: Pressure to produce is positively associated with role overload.

\subsection{Negative Affectivity}

As previously mentioned, NA is a stable personality trait that is associated with a more negative self-view and experiencing more negative emotions and moods (Watson, 2000; Watson \& Clark, 1984). High NA individuals are more likely to focus on negative aspects of their environment, workplace, and situations in general. These individuals take a negative slant on situations, which often alters the way these people react in different positions (George, 1992). When compared to their low NA counterparts, who often view the world, themselves, and the environment in a more positive light (Watson \& Clark, 1984), individuals high in NA are likely to respond to situations more negatively.

\subsection{Pressure to Produce and Negative Affectivity}

In terms of the pressure to produce - outcome associations, person-situation theories provide a useful framework for examining the impact of NA. Person-situation theories (Mischel \& Shoda, 1995) suggest that personality and situational variables are likely to interact. Further, this interaction, as opposed to either the personality or situational variable by itself, will provide a more accurate depiction of how employees respond to certain situations. In our study, pressure to produce is a situational variable that we expected to be associated with undesirable outcomes.

However, person-situation theory suggests that NA is a personality variable that is likely to impact how employees respond to pressure to produce. As high NA individuals are likely to react more strongly to negative or threatening situations (Bruck \& Allen, 2003; George, 1992), we suggest that this personality variable will intensify the negative associations between pressure to produce and desired job outcomes. In particular, low NA individuals are likely to recognize that pressure to produce is necessary and be better able to control how they react to the situation. 
Conversely, individuals high in NA will dwell on the pressure to produce. They are more likely to think negatively about the pressure and have it impact how they feel about the job, organization, and their roles. Based on this logic, we posit that the personality characteristic of high NA is likely to intensify the effect of pressure to produce on the three individual outcomes we examine in this study. Thus, we predict that:

Hypothesis 2a: Negative affectivity will moderate the negative relationship between pressure to produce and job satisfaction such that the relationship is strongest when negative affectivity is highest.

Hypothesis $2 \mathrm{~b}$ : Negative affectivity will moderate the negative relationship between pressure to produce and POS such that the relationship is strongest when negative affectivity is highest.

Hypothesis 2c: Negative affectivity will moderate the positive relationship between pressure to produce and role overload such that the relationship is strongest when negative affectivity is highest.

\section{Method}

\subsection{Sample and Procedure}

The sample for this study consisted of 220 full-time working individuals, each of whom worked at least 25 hours per week on a computer (technology end-users). These respondents worked in a large range of organizations (e.g., accountants, government employees, receptionists). Respondents were recruited by members of a senior-level business class in a Midwestern university. Each student was given the opportunity to distribute three surveys and have them completed by employees working full-time (at least 35 hours per week, and at least 25 of those hours had to be spent on a computer). The companies where the employees worked had to have 10 or more employees. In exchange for assisting with the data collection, students received course credit for completed surveys.

This technique for data collection has been utilized successfully in a number of research efforts (e.g., Harris, Marret, and Harris, 2011; Rotondo, Carlson, \& Kincaid, 2003). Each of the surveys contained a cover letter, which explained that participants were being invited to participate in a study by university researchers. The cover letter also explained that the topic of the study was workplace relationships, technology, and job attitudes. On the first page of the survey, the respondents were required to provide the student's name, and on the last page, were required to provide their phone numbers. To increase the confidence in our findings and discourage some issues related to the truthfulness of who completed the responses, one of the authors randomly selected survey respondents to call and ask innocuous questions (e.g., "What section of the questionnaire did you find to be the most interesting?"). Based on the responses to initial questions, the researcher making the phone calls asked follow-up questions about more objective information that was provided on the survey (i.e., "How many years have you been with the organization?" or "How many coworkers do you regularly interact with?"). Additionally, students were informed at the beginning of the process that if there were any questions or doubts that the respondents did not complete the questionnaire, no course credit would be given. Although not foolproof, we found no suspicions about respondents completing the survey and we feel that our procedures helped to ensure the truthfulness of responses.

In total, 303 surveys were distributed from which 220 completed surveys (73\% response rate) were returned. The sample was $62 \%$ female, had a mean age of 37.13 years, an average organizational tenure of 7.00 years, and worked an average of 43.30 hours per week.

\subsection{Measures}

All survey items were responded to on a 5-point Likert scale, with anchors for the scale as "strongly disagree" (1) and "strongly agree" (5). The scale items were averaged to create an overall mean for each variable, and coded such that high values represent high levels of the constructs.

\subsubsection{Pressure to Produce}

Pressure to produce was measured with Harris, Marett, and Harris's (2013) 5-item scale $(\alpha=.71)$. A sample item was "Management requires people to work extremely hard."

\subsubsection{Negative Affectivity}

Negative affectivity was measured with Zellars, Tepper, and Duffy's (2002) 4-item scale $(\alpha=.85)$. A sample item was "I often feel upset."

\subsubsection{Job Satisfaction}

We measured job satisfaction with Cammann, Fichman, Jenkins, and Klesh's (1979) 3-item scale ( $\alpha=.94)$. A sample item was "All in all, I am satisfied with my job." 


\subsubsection{Role Overload}

Role overload was measured with Peterson et al's (1995) 5-item scale $(\alpha=.92)$. A sample item was "I feel overburdened in my role."

\subsubsection{Perceived Organizational Support}

We measured POS with Eisenberger et al's (1990) 9-item scale $(\alpha=.94)$. A sample item was "The organization really cares about my well-being."

\subsection{Control Variables}

In this study we controlled for age and hours worked per week.

\subsection{Analysis Technique}

Hypotheses were tested using hierarchical moderated regression analyses, with separate analyses conducted for each of the three outcome variables. Each analysis consisted of four steps. In the first step, we entered the two control variables. The centered (Aiken \& West, 1991) pressure to produce term was entered in step 2 and it was in this step that we tested Hypotheses 1a, 1b, and 1c. In the third step we entered the centered NA term. Finally, in the fourth and final step, we entered the interaction terms formed between the centered pressure to produce and NA terms, and it was in this final step that we tested Hypotheses $2 \mathrm{a}, 2 \mathrm{~b}$, and $2 \mathrm{c}$.

\section{Results}

Means, standard deviations, and correlations among the study variables are shown in Table 1.

Table 1. Means, standard deviations, and correlations among the study variables

\begin{tabular}{lrrrcccccc}
\hline Variable & Mean & SD & 1 & 2 & 3 & 4 & 5 & 6 & 7 \\
\hline 1. Pressure to Produce & 3.30 & 0.67 & - & & & & & \\
2. Negative Affectivity & 2.39 & 0.79 & $.26^{* *}$ & - & & & & \\
3. Job Satisfaction & 4.05 & 0.79 & $-.18^{* *}$ & $-.34^{* *}$ & - & & & \\
4. Role Overload & 2.66 & 0.88 & $.48^{* *}$ & $.44^{* *}$ & $-.41^{* *}$ & - & & \\
5. POS & 3.56 & 0.77 & $-.27^{* *}$ & $-.33^{* *}$ & $.56^{* *}$ & $-.42^{* *}$ & - & \\
8. Age & 37.13 & 12.82 & .10 & -.08 & .11 & .06 & -.12 & - \\
9. Hours Worked Per & 43.30 & 8.92 & $.16^{*}$ & .07 & -.11 & $.23^{* *}$ & $-.22^{* *}$ & $.15^{*}$ & - \\
\hline
\end{tabular}

$\mathrm{N}=220, \mathrm{POS}=$ Perceived Organizational Support

$* p<.05 . * \mathrm{p}<.01$.

As expected, our dependent variables are significantly correlated. However, we only had one correlation above .48, suggesting that common method variance (CMV) was not a pervasive problem in this study (Spector, 2006).

Results of the hierarchical moderated regression analysis are presented in Table 2. As the table indicates in step 2 of our analyses, pressure to produce is significantly related to job satisfaction ( $(=-.21, p<.01)$, $\mathrm{POS}(\beta=-.28, p<.01)$, and role overload $(\beta=.60, p<.01)$. These results provide support for Hypotheses $1 \mathrm{a}, 1 \mathrm{~b}$, and $1 \mathrm{c}$. As shown in step 3 of each of the analyses, NA is significantly related to the outcome variables. 
Table 2. Hierarchical regression results

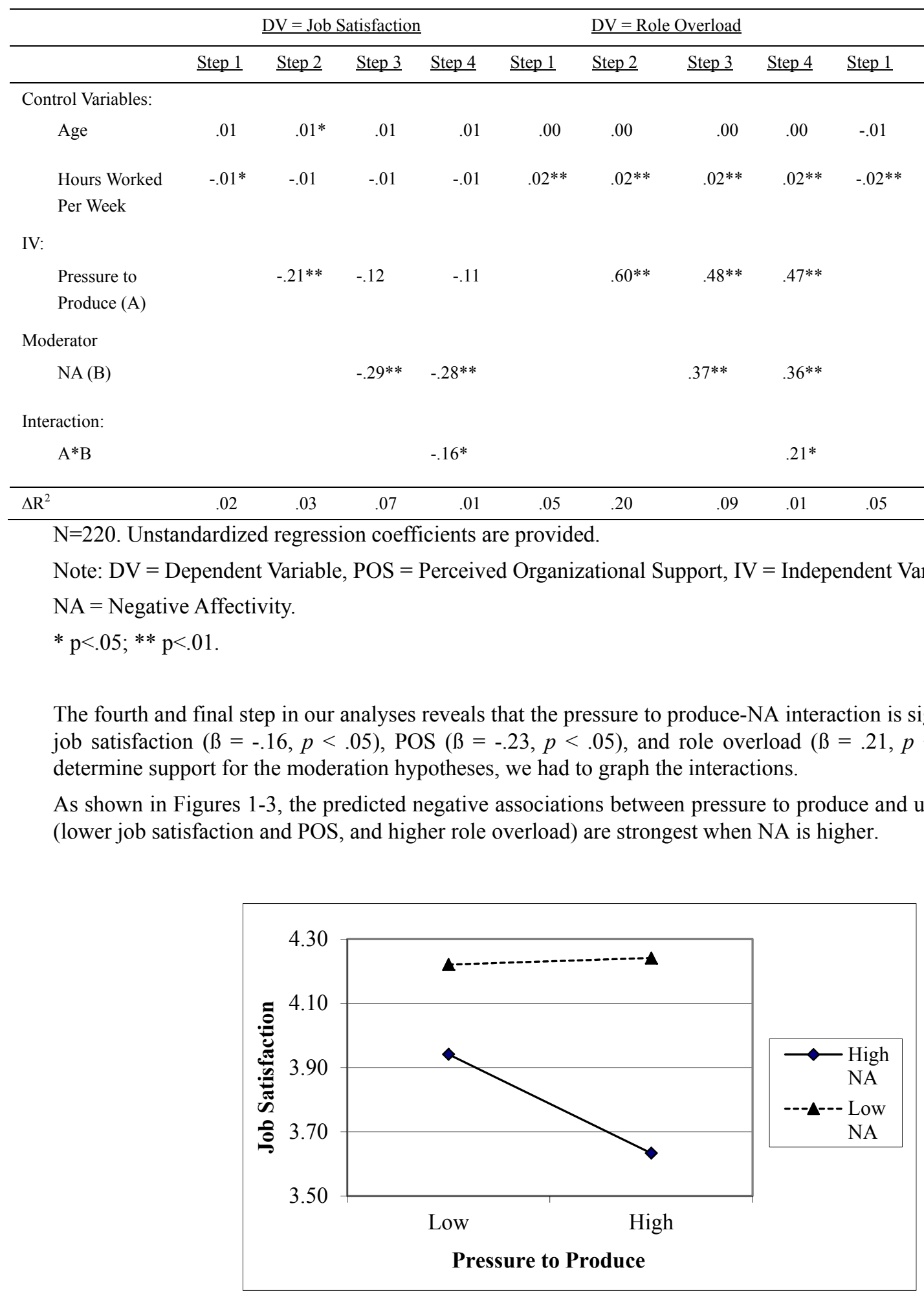

Figure 1. Interaction between pressure to produce and NA predicting job satisfaction 


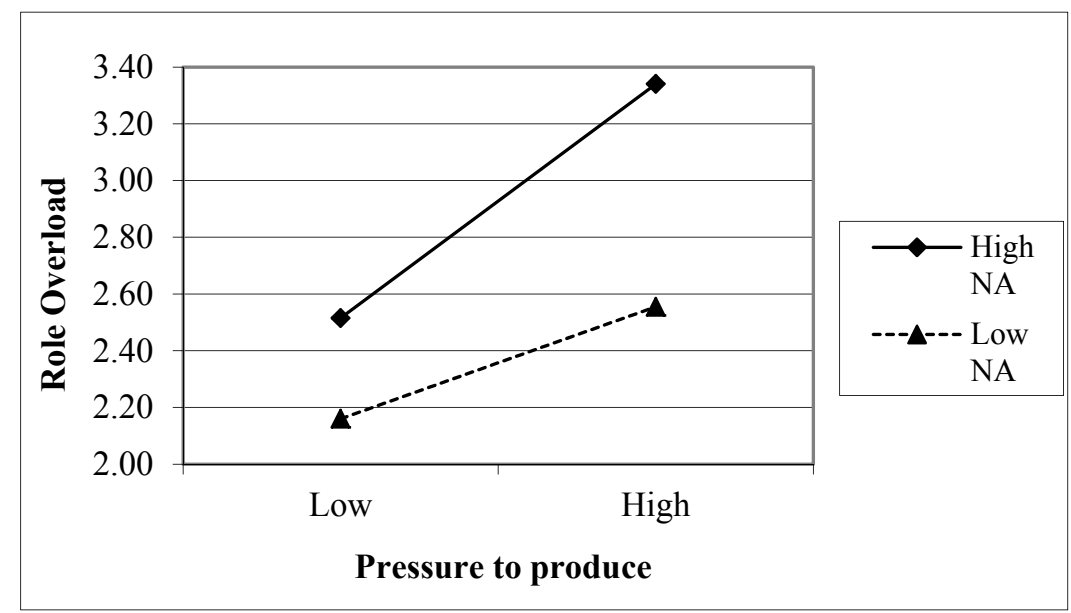

Figure 2. Interaction between pressure to produce and NA predicting role overload

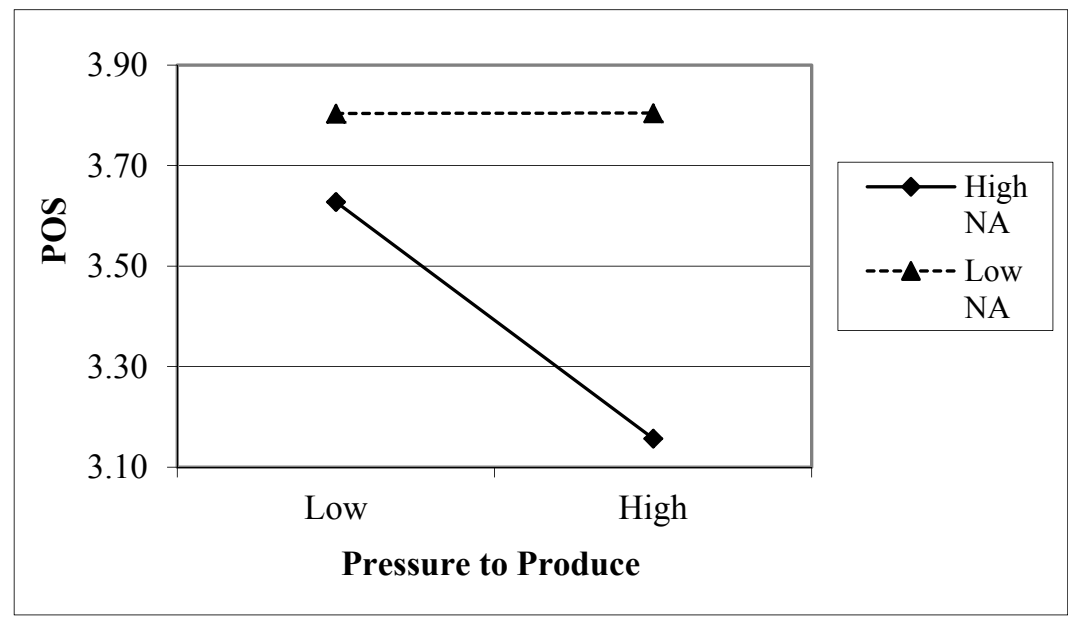

Figure 3. Interaction between pressure to produce and NA predicting POS

In total, our significant results and these graphical depictions of the relationships provide support for Hypotheses $2 \mathrm{a}$, $2 \mathrm{~b}$, and $2 \mathrm{c}$.

\section{Discussion}

The purpose of this study was twofold. First, we set out to determine the impact of pressure to produce on important job outcomes for technology end-users. We found that pressure to produce was associated with undesirable individual consequences (lower job satisfaction and POS, and higher role overload). These findings point to the notion that managers should be aware that although pressure to produce may have positive performance-related effects, negative consequences could also occur.

The second goal of our study was to determine if there was a person-situation interaction when NA impacted how pressure to produce was related to our consequences. Our findings for all three outcomes revealed that NA intensified the associations between pressure to produce and negative job outcomes. This set of results indicates that not all individuals are likely to react to pressure to produce in the same way, as there is a personality characteristic that impacts the relationships between the situation and outcomes examined.

\subsection{Limitations and Suggestions for Future Research}

Although this study had a number of strengths, there are limitations that must be acknowledged. First, all of our data were collected at the same time from the same individuals, which could point to issues related to CMV. Even though our study had moderate correlations, which indicate CMV might have been less of a concern, we encourage future 
researchers to gather data from multiple individuals. A second limitation is that our significant interactions explained only $1-2 \%$ of the variance. Acknowledging this amount is small, there is considerable research that has shown the practical impact and real dollar implications of small effect sizes (Abelson, 1985; Fichman, 1999). A third limitation is that although our study showed that there was a significant interaction between pressure to produce and NA, we were unable to determine the specifics of why. To help answer this question, we encourage future researchers to design studies with the "why" research question in mind.

A few other avenues for future research include examining performance-related outcomes as well as attitudinal and stress outcomes in the same study. Most of the reasons behind having pressure to produce relate to employee motivation and ultimately performance. Thus, a study with both "good" and "bad" outcomes of pressure in the same study would be beneficial. A few other directions for future research relate to our sample. It would be insightful to determine if other samples, composed of non-technology end-users or a mixed group of end-users and non end-users, would reveal similar results. A study with a different sample would help to determine the generalizability or potential boundary conditions of the relationships we examined. A different feature of study worthy of future research relates to the technology component. Are the undesirable associations with pressure to produce a function of constant connectivity? Maybe it is some function of employees feeling like their work can be constantly tracked? There might be other explanations related to our findings with technology end-users comprising the sample, and we hope future researchers are able to better answer these questions.

\subsection{Conclusion}

This study sheds light on the deleterious attitudinal and stress-related outcomes of pressure to produce for technology end-users. It also showed that while the negative effects of pressure to produce are present, they are intensified for individuals who are high in negative affectivity. We hope future researchers will extend our findings, and further our findings by answering some of the unanswered questions in our study.

\section{References}

Abelson, R. (1985). A variance explanation paradox: When a little explains a lot. Psychological Bulletin, 97, 129-133. http://dx.doi.org/10.1037//0033-2909.97.1.129

Aiken, L. S., \& West, S. G. (1991). Multiple regression: Testing and interpreting interactions. Thousand Oaks: Sage.

Alasoini, T., Ramstad, E., Heikkiiä, A., \& Ylöstalo, P. (2010). Workplace innovation in Finland: Toward sustainable productivity growth? Budapest Management Review, 41(9), 2-16.

Ayyagari, R., Grover, V., \& Purvis, R. (2011). Technostress: Technological Antecedents and Implications. MIS Quarterly, 35, 831-858.

Bruck, C. S., \& Allen, T. D. (2003). The relationship between big five personality traits, negative affectivity, type A behavior, and work-family conflict. Journal of Vocational Behavior, 63, 457-472. http://dx.doi.org/10.1016/s0001-8791(02)00040-4

Cammann, C., Fichman, M., Jenkins, D., \& Klesh, J. (1979). The Michigan organizational assessment questionnaire. Ann Arbor, MI: University of Michigan.

Demircan Çakar, N., \& Yildiz, S. (2009). The effects of organizational justice on job satisfaction: Is "perceived organizational support" a mediator? Electronic Journal of Social Sciences, 8(28), 68-90.

Eisenberger, R., Fasolo, P., \& Davis-LaMastro, V. (1990). Perceived organizational support and employee diligence, commitment, and innovation. Journal of Applied Psychology, 75, 51-59. http://dx.doi.org/10.1037//0021-9010.75.1.51

Ferri-Reed, J. (2014). Millennialzing the workplace. Journal for Quality and Participation, 37(1), 13-14.

Fichman, M. (1999). Variance explained: Why size does not (always) matter. Research in Organizational Behavior, 21, 295-331.

George, J. M. (1992). The role of personality in organizational life: Issues and evidence. Journal of Management, 18, 185-213. http://dx.doi.org/10.1177/014920639201800201

Harris, K., Lambert, A., \& Harris, R. (2013). HRM effectiveness as a moderator of the relationships between abusive supervision and technology work overload and job outcomes for technology end users. Journal of Applied Social Psychology, 43, 1686-1695. http://dx.doi.org/10.1111/jasp.12122 
Harris, K. H., Marett, K., \& Harris, R. B. (2013). An Investigation of the Impact of Abusive Supervision on Technology End-Users. Computers in Human Behavior, 29, 2480-2489. http://dx.doi.org/10.1016/j.chb.2013.06.008

Harris, K. J., Marett, K., \& Harris, R. B. (2011). Technology-related pressure and work-family conflict: Main effects and an examination of moderating variables. Journal of Applied Social Psychology, 41, 2077-2013. http://dx.doi.org/10.1111/j.1559-1816.2011.00805.x

LePine, J. A., Podsakoff, N. P., \& LePine, M. A. (2005). A meta-analytic test of the challenge stressor-hindrance stressor framework: An explanation for inconsistent relationships among stressors and performance. Academy of Management Journal, 48, 764-775. http://dx.doi.org/10.5465/amj.2005.18803921

Majer, C., Laumer, S., Weinert, C., \& Weitzel, T. (2015). The effects of technostress and switching stress on discontinued use of social networking services: a study of Facebook use. Information Systems Journal, 25(3), 275-308. http://dx.doi.org/10.1111/isj.12068

Mischel, W., \& Shoda, Y. (1995). A cognitive-affective system theory of personality: Reconceptualizing situations, dispositions, dynamics, and invariance in personality structure. Psychological Review, 102, 246-268. http://dx.doi.org/10.1037/0033-295x.102.2.246

Peterson, M. F., Smith, P. B., Akande, A., Ayestaran, S., Bochner, S., Callan, V., ... Viedge, C. (1995). Role conflict, ambiguity, and overload: A 21-nation study, Academy of Management Journal, 38, 429-452. http://dx.doi.org/10.2307/256687

Rhoades, L., \& Eisenberger, R. (2002). Perceived organizational support: A review of the literature. Journal of Applied Psychology, 87, 698-714. http://dx.doi.org/10.1037//0021-9010.87.4.698

Rizzo, J. R., House, R. J., \& Lirtzman, S. (1970). Role conflict and ambiguity in complex organizations. Administrative Science Quarterly, 15, 150-163. http://dx.doi.org/10.2307/2391486

Rotondo, D., Carlson, D., \& Kincaid, J. (2003). Coping with multiple dimensions of work-family conflict. Personnel Review, 32, 275-297. http://dx.doi.org/10.1108/00483480310467606

Slocum, J. J., Cron, W., Hansen, R., \& Rawlings, S. (1985). Business Strategy and the Management of Plateaued Employees. Academy of Management Journal, 28(1), 133-154.

Spector, P. E. (1997). Job satisfaction: Application, assessment, causes and consequences. Thousand Oaks, CA: SAGE. http://dx.doi.org/10.4135/9781452231549

Spector, P. E. (2006). Method variance in organizational research. Organizational Research Methods, 9, 221-232. http://dx.doi.org/10.1177/1094428105284955

Watson, D. (2000). Mood and temperament. New York: Guilford Press.

Watson, D., \& Clark, L. A. (1984). Negative affectivity: The disposition to experience aversive emotional states. Psychological Bulletin, 96, 465-498. http://dx.doi.org/10.1037/0033-2909.96.3.465

Zellars, K. L., Tepper, B. J., \& Duffy, M. K. (2002). Abusive supervision and subordinates' organizational $\begin{array}{lllll}\text { citizenship behavior. Journal of Applied Psychology, 87, } & \text { 1068-1076. }\end{array}$ http://dx.doi.org/10.1037//0021-9010.87.6.1068 